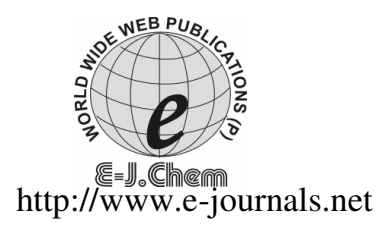

\author{
ISSN: 0973-4945; CODEN ECJHAO \\ E-Journal of Chemistry \\ 2011, 8(2), 507-512
}

\title{
Oligodeoxynucleotide Containing Disulphide Bond Stabilizes Triplex DNA Structure
}

\author{
AJAY KUMAR \\ Apeejay Stya University \\ Palwal Sohna Road, Gurgaon, Haryana, India \\ ak.gupta59@ rediffmail.com \\ Received 24 May 2010; Accepted 27 August 2010

\begin{abstract}
The triplex formation of disulphide containing oligonucleotide with duplex DNA using melting temperature studies is reported. The stability of the triplex formed with disulphide containing oligonucleotide was compared with unmodified oligonucleotide and $\mathrm{C}-5$ propyne deoxyuridine containing oligonucleotide. Melting temperature $\left(\mathrm{T}_{\mathrm{m}}\right)$ values of the triplexes formed with disulphide containing oligonucleotide were found to be $37^{\circ} \mathrm{C}$ and $46{ }^{\circ} \mathrm{C}$ at $\mathrm{pH}$ 7 and 6 respectively. The triplexes formed with $\mathrm{C}-5$ propyne deoxyuridine substituted oligonucleotide showed $\mathrm{T}_{\mathrm{m}}$ values at $27{ }^{\circ} \mathrm{C}$ and $42{ }^{\circ} \mathrm{C}$ at $\mathrm{pH} 7$ and 6 . The $\mathrm{T}_{\mathrm{m}}$ values of the triplexes formed with unmodified oligonucleotide were found to be $18{ }^{\circ} \mathrm{C}$ and $32{ }^{\circ} \mathrm{C}$ at $\mathrm{pH} 7$ and 6 respectively. This clearly demonstrates that disulphide containing oligonucleotide stabilzes triplex DNA structure better than unmodified oligonucleotide as well as C-5 propyne deoxyuridine containing oligonucleotide when targeted with duplex DNA at both the mentioned $\mathrm{pH}$ values.
\end{abstract}

Keywords: C-5 Thiopropyne substituted oligonucleotides, $\mathrm{T}_{\mathrm{m}}$ studies, Triplex formation, C-5 Propyne deoxyuridine oligonucleotides, Disulphide containing oligonucleotide.

\section{Introduction}

High affinity, sequence specific recognition of double stranded DNA by oligonucleotide analogues is important for the selective control of gene expression ${ }^{1-3 .}$ The triple helix formation with RNA single strand may interfere with transcription in DNA and translation in $\mathrm{RNA}^{4,5}$. Since the discovery of the poly $\mathrm{U}$, poly A poly U nucleic acid triple helix, variety of base triplex motifs other than U-A:U have been characterized ${ }^{6-9}$. However, two ${ }^{10-11}$ structural motifs have become popular. These two motifs differ in the composition of base triplet and strand polarity. In pu-pu:py motif the third strand is purine rich and is in an antiparallel 
orientation to the Hoogsteen side of the purine strand of the Watson Crick duplex. This motif exhibits G -G C, A- A: T and T- A: T base triplet ${ }^{12}$. In py-pu:py motif the third strand consists only of pyrimidine bases and is paired to the Hoogsteen side of purine strand in a parallel fashion. The py-pu:py motif shows T-A:T and C+- G: $\mathrm{C}^{9},{ }^{10}$ base triplets. Formation of the C- G: $\mathrm{C}$ triplet requires condition of low $\mathrm{pH}(<6.0)$ necessary for protonation of the third strand cytosine. The free nucleotide has a pK of 4.5 but this is elevated when oligonucleotides containing cytosine is used for triplex formation. The increase in $\mathrm{pK}$ depends on number and location of cytosines ${ }^{13}$. Several cytosine analogues have been synthesized in attempt to overcome this restriction ${ }^{14-31}$. Till now most of the bases analogues which have been prepared for triplex formation are derivatives of cytosine and have been designed to overcome the requirement for conditions of low $\mathrm{pH}$. It is well known that $\mathrm{C}+\mathrm{G}-\mathrm{C}$ is more stable than TAT. An approach different for increasing triplex stability is to modify the TAT triplet. Few efforts have been made to improve the stability of TAT triplet ${ }^{32-41}$. Experiments with 5- propargylamino- $\mathrm{dU}$ as a charged analogue of thymine to stabilize TAT triplet have been described ${ }^{35}$. Here, in we describe, stabilization of triplex using disulphide containing oligonucleotide. Using an earlier described method ${ }^{42}$ thiol groups were incorporated at two adjacent thymidines of TTCTTTCTTTTC (Table 1). There after disulphide bond (Table 1) was made by oxidizing thiol groups ${ }^{43}$. The disulphide containing oligonucleotide thus prepared was targeted with double stranded oligonucleotide. For comparison, unmodified as well as C-5 propyne deoxyuridine containing oligonucleotides were also studied. Thermal denaturation studies showed that disulphide containing oligonucleotide was superior to unmodified as well as propyne deoxyuridine modified oligonucleotides.

\section{Experimental}

The unmodified oligonucleotides and C-5 thiopropyne substituted deoxyuridine containing oligonucleotide were synthesized, deprotected, purified and analysed (base composition) as described else where ${ }^{42}$. Propyne deoxyuridine containing oligonucleotide was synthesized using 5-(1- propyne) -2'- deoxyuridine phosphoramidite (Glen Research). The propyne deoxyuridine containing oligonucleotide was deprotected and purified as the unmodified oligonucleotides. The preparation of disulphide containing oligonucleotide and purification was carried out as described earlier ${ }^{43}$. The purification of the oligonucleotide, $\mathbf{3}$, was carried out using 5'CCTCTTAAGAAAGAAAAGCTTCCT3', 5, as template. The 15 nmole of $\mathbf{3}$ and $15 \mathrm{nmole}$ of purified 5 were mixed in buffer $\left(100 \mathrm{mM} \mathrm{NaCl}, 10 \mathrm{mM} \mathrm{MgCl} \mathrm{Mn}_{2}\right.$ and $10 \mathrm{mM}$ PIPES) and exposed to air for 5-6 h and left overnight at $4{ }^{\circ} \mathrm{C}$. The solution was dialyzed against water $(4 \times 2.0 \mathrm{~L})$ for $16 \mathrm{~h}$ and dried in Speed Vac concentrator. The dried oligonucleotides thus obtained were purified by gel electrophorsis on $20 \%$ polyacrylamide containing $7 \mathrm{M}$ urea, followed by crush, soak and dialysis methods. The oligonucleotide, $\mathbf{3}$, thus obtained was quantitated by UV absorbance at $260 \mathrm{~nm}$. The molar extinction coefficient for oligonucleotide containing the non-natural residues was determined by taking molar extinction coefficient of 5- (1-propyl)-2'- deoxy uridine (Glen Research), $\varepsilon=3.2 \times 10^{-3}$.

\section{Melting temperature $\left(T_{m}\right)$ studies}

Solutions for the thermal denaturation studies were prepared by mixing 1:1 of a given DNA oligomers and double stranded DNA $(1.5 \mu \mathrm{M}$ each) in a buffer $(100 \mathrm{mM}, \mathrm{NaCl}, 100 \mathrm{~m} \mathrm{M}$ $\left.\mathrm{MgCl}_{2}, 100 \mathrm{~m} \mathrm{M} \mathrm{NaPIPES}\right)$ at $\mathrm{pH} 6$ and 7 respectively. The mixtures were heated to $90{ }^{\circ} \mathrm{C}$ and allowed to cool down slowly to room temperature prior to the melting experiments. The melting studies were carried out in Teflon-Stoppered $1 \mathrm{~cm}$ path length quarts cells under 
nitrogen atmosphere using a varian carry UV- Vis spectrophotometer equipped with thermo programmer. Absorbance $(260 \mathrm{~nm})$ was monitored while temperature was raised from $10{ }^{\circ} \mathrm{C}$ to $90{ }^{\circ} \mathrm{C}$ at a rate of $0.5^{\circ} \mathrm{C} / \mathrm{min}$.

\section{Results and Discussion}

The sticks structure of disulphide bond formed between two adjacent C-5 thiopropyne deoxyuridines is shown in Figure 1. The oligonucleotide sequences synthesized are tabulated in Table $1 . \mathrm{T}_{\mathrm{m}}$ data of the triplexes determined by thermal denaturation studies is tabulated in Table 2. The $\mathrm{T}_{\mathrm{m}}$ profiles of triplexes are shown in Figures 2 - 4.

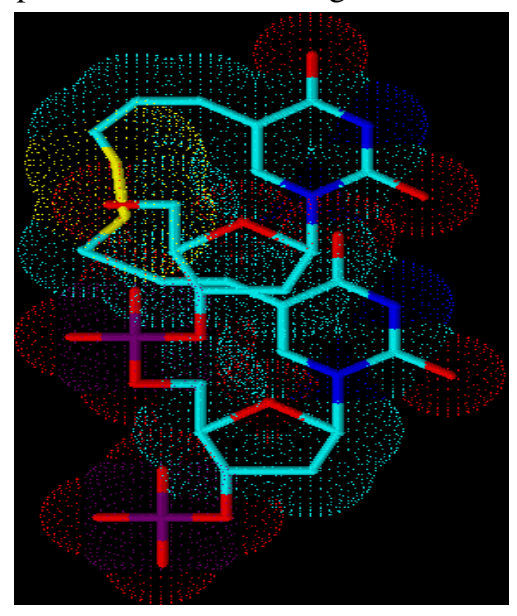

Figure 1. The disulphide bond formed between two adjacent C-5 thiopropyne deoxyuridines

Table 1. The oligonucleotide sequences synthesized

\begin{tabular}{cc}
\hline S.No & \multicolumn{1}{c}{ Oligonucleotide sequences } \\
\hline 1 & 3' TTCTTTCTTTTC5' \\
2 & S-S \\
I I & P P \\
& I I \\
3 & TTCTTCTTTC5' \\
& 3' TTCTTTCTTTTC5' \\
& P=. Propyne \\
4 & 5'GGACTCTATCAGAAAGAAAAGGGACTCTATCAGAG3' \\
& 3'CCTGAGATAGTCTTTCTTTCCCTGAGATAGTCTC5' \\
5 & 5'CCTCTTAAGAAAGAAAAGCTTCCT3'
\end{tabular}

Table 2. $\mathrm{T}_{\mathrm{m}}$ Data of triplexes

\begin{tabular}{ccl}
\hline Triplexes & $\mathrm{T}_{\mathrm{m}}{ }^{0} \mathrm{C} 7 \mathrm{pH}$ & \multicolumn{1}{c}{$\mathrm{T}_{\mathrm{m}}{ }^{0} \mathrm{C} 6 \mathrm{pH}$} \\
\hline 4 & 72.95 & 72.42 \\
$4+1$ & $18.0,72.12$ & $32.0,72.50$ \\
$4+2$ & $37.0,72.12$ & $46.0,72.30$ \\
$4+3$ & $27.0,72.12$ & $42.0,72.42$ \\
\hline
\end{tabular}




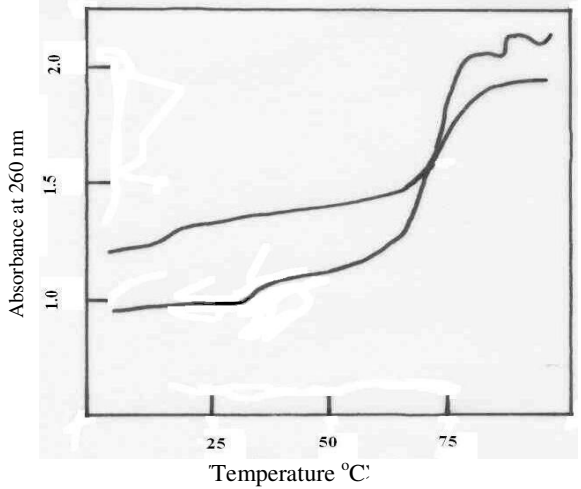

Figure 2. Tm profiles of $4+1$ at $6 \mathrm{pH}$ (lower one) and $7 \mathrm{pH}$ (upper one)

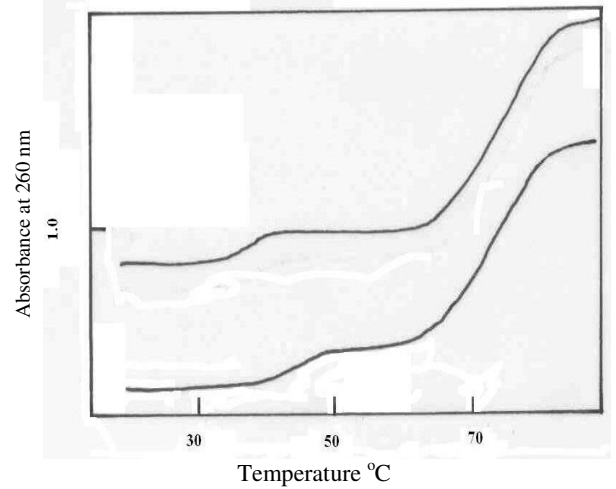

Figure 3. Tm profiles of $4+2$ at $6 \mathrm{pH}$ (lower one) and $7 \mathrm{pH}$ (upper one)

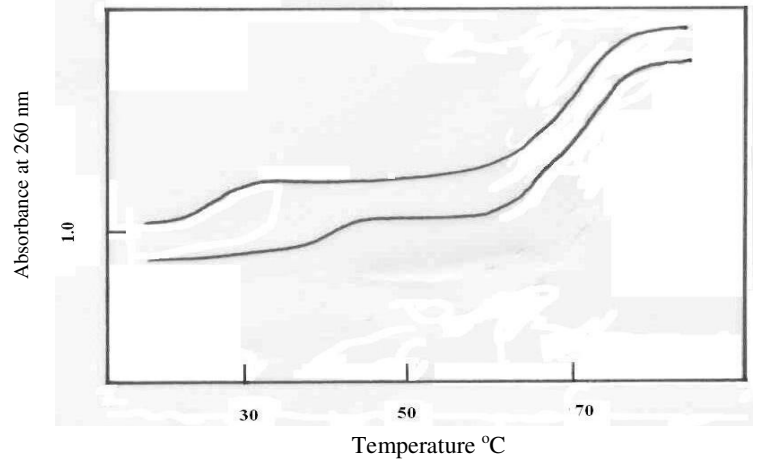

Figure 4. $\mathrm{T}_{\mathrm{m}}$ profiles of $4+3$ at $6 \mathrm{pH}$ ( lower) and $7 \mathrm{pH}$ (upper)

The denaturation studies resulted in two transition in all the cases. The first transition corresponds to the melting of triple helix and the second transition to the duplex target, as shown in Figure 2-4. The $\mathrm{T}_{\mathrm{m}}$ values of triplexes are higher in case of disulphide containing oligonucleotide, $\mathbf{2}$, as compared to unmodified oligonucleotide, $\mathbf{1}$, as well as C-5 propyne deoxyuridine containing oligonucleotide, $\mathbf{3}$, at both the $\mathrm{pH}$ values. The $\mathrm{T}_{\mathrm{m}}$ values of the triplexes were found to be higher in case of disulphide containing oligonucleotide by $19{ }^{\circ} \mathrm{C}$ and $14{ }^{\circ} \mathrm{C}$ as compared to unmodified oligonucleotide and by $10{ }^{\circ} \mathrm{C}$ and $4{ }^{\circ} \mathrm{C}$ as compared to propyne deoxyuridine containing oligonucleotide at $\mathrm{pH} 7$ and 6 respectively. Hence disulphide containing oligonucleotide is a better candidate for targeting a genomic DNA than the unmodified oligonucleotide, $\mathbf{1}$, as well as propyne deoxyuridine modified oligonucleotide, $\mathbf{3}$. The triplex stabilization appears to be due to the presence of disulphide bond which reduces flexibility in the disulphide containing oligonucleotide sequence. Earlier Glick et $a l .^{44-45}$ have reported synthesis of conformationally restricted DNA hairpin and showed by optical melting studies that disulphide cross linked increases $\mathrm{T}_{\mathrm{m}}$ by $21^{\circ} \mathrm{C}$ relative to the wild type sequence. Kool et al. ${ }^{42}$ have synthesized bicyclic oligonucleotides by making a disulphide bond in between the circular DNA molecule and have shown that bicylic oligonucleotide has very high affinity for single stranded oligonucleotide. Jone et al. ${ }^{33}$ have made use of oligonucleotides containing a covalent conformationally restricted phosphodiester analog for high-affinity triple helix formation; the riboacetal internucleotide linkage. Froehler et al. ${ }^{34}$ have used oligodeoxynucleotides containing C-5 propyne analogs of 2'-deoxyuridine and 2'-deoxycytidine for stabilization of triplex. From this it become clear that 
conformation restriction as well as $\pi-\pi^{*}$ interactions promote triplex stabilization. In the present case we have made use of both the techniques. The thiopropyne modified oligonucleotide contains triple bonds as well as a disulphide bond between the two adjacent deoxyuridines to restrict the conformation and hence stabilized triple helix.

\section{Conclusion}

Our $\mathrm{T}_{\mathrm{m}}$ study results clearly show that disulphide containing oligonucleotide stabilizes the triplex DNA structure significantly better than both unmodified oligonucleotide as well as propyne deoxyuridine containing oligonucleotide at both the $\mathrm{pH}$ values. Thus disulphide containing oligonucleotide can be better transcription inhibitor.

\section{References}

1. Uhlman E and Peyman A, Chem Rev., 1990 , 90, 543-584.

2. Goodchild J, Bioconjugate Chem., 1990 , 1, 165-185.

3. English U and Ganss D, Angew Chem Int Ed., 1991, 103, 629-646.

4. Thuong N T and Helene C, Angew Chem Int Ed., 1993, 105, 697-723.

5. Felsenfeld G, Davis D and Rich A, J Am Chem Soc., 1957, 79, 2023-2024.

6. Howard F B, Frazier J, Lipsett M N and Miles T H, Biochem Biophys Res Commun., 1964, 17, 93-97.

7. Morgan A B and Well R D, J Mol Biol., 1968, 37, 63-67.

8. Le Doan T, Perrovault L, Praseuth D; Habhoub N, De Cout J, Thuoug N T, Lhomme J Helene C, Nucleic Acids Res., 1987, 15, 7749-7760.

9. Moser H E and Dervan P B, Sci., 1987, 238(4827), 645-650.

10. Francois T, Behmoarar C, Helene C, Nucleic Acids Res., 1988, 16(24), 11431-11440.

11. Cooney M, Czernuszewicz G, Postel E H, Flint S J and Hogan M E, Sci., 1988, 241, 456-459.

12. Beal P A and Dervan P B, Sci., 1991, 251, 1360-1363.

13. Assensio J L Lane A N, Dhesi J Bergqvist S and Brown T, J Mol Biol., 1988, 275, 811-822.

14. Povsic T J and Dervan P B, J Am Chem Soc., 1989, 111, 3059 -3061.

15. Xodo L E, Manzini G, Quadifoglio F, Vander Marel G and Van Boom J, Nucl Acids Res., 1991, 19, 5625-5631.

16. Frochler B C and Ricca D J, J Am Chem Soc., 1992, 114, 8320-8322.

17. Huang C Y, Bi G and Miller P S, Nucl Acids Res., 1996, 24, 2606 -2613.

18. Ono A, Ts'O P O P and Kan I, J Am Chem Soc., 1991, 113, 4032-4033.

19. Miller P S, Bhan P, Cushman C D and Trapane T L, Biochem., 1992, 31(29) 6788- 6793.

20. Jetter M C and Hobbs F W, Biochem., 1993, 32, 3249-3254.

21. Bates P J, Langhton C A, Jenkins T C, Capaldi D C, Roselt P D, Reese C B and Neidle S, Nucl Acids Res., 1996, 24, 4176-4184.

22. Hildbrand S, Blasser A, Parel S P and Lenmann, C J, J Am Chem Soc., 1997, 119, 5499-5511.

23. Hildbrand S and Leumann C, Angew Chem Int Ed., 1996, 35, 1968-1970.

24. Barawkar D A, Rajeev K G, Kumar V A and Ganesh K N, Nucleic Acids Res., 1996, 24,1229-1237.

25. Rajeev K G, Jadhav V R and Ganesh K N, Nucl Acids Res., 1997, 25, 4187- 4193.

26. Tung C H, Breslabourer K J and Stein S, Nucl Acids Res., 1993, 21, 5489-5494.

27. Sund C, Puri N and Chattopadhyaya J, Tetrahedron, 1996, 52, 12275-12290.

28. Sund C, Puri N and Chattopahyaya J, Nucleosides Nucleotides, 1997, 16, 755-760. 
29. Cuenoud B, Casset F, Husken D, Natt F, Wolf R M, Altmann K H, Martin P and Moser H E, Angew Chem Int Ed., 1998 37, 1288- 1291.

30. Blommers T J J, Nalt F, Jahnke W and Cuenoud B, Biochem., 1998, 37, 17714- 17725.

31. Nara H, Ono A and Matsuda A, Bioconjugate Chem., 1995, 6, 54-61.

32. Gryaznov S and Chen J K, J Am Chem Soc., 1995, 117, 3143-3144.

33. Jones R J, Swaminathan S, Milligan J F, Wadwani S, Froehler B C and Metteucci M.D, J Am Chem Soc., 1993, 115, 9816-9817.

34. Froehler B C, Wadwani S, Terhorst T J and Gerrard S R, Tetrahedron Lett., 1992, 33, 5307-5310.

35. Bijapur J, Keppler M D, Bergqvist S, Brown T and Fox K R, Nucl Acids Res., 1999, 27, 1802-1809.

36. Gowers D M, Bijapur J, Brown T and Fox K R, Biochem., 1999, 38, 13747-13758.

37. Osborne S D, Powers V E C, Rusling D A, Lack O, Fox K R and Brown T, Nucl Acids Res., 2004, 32, 4439-4447.

38. Puri N, Majumdar A, Cuenoud B, Miller P S and Seidman M M, Biochem., 2004, 43, 1343-1351.

39. Sollogoub M, Darby R A J, Cuenoud B, Brown T and Fox K R, Biochem., 2002, 41, 7224-7231.

40. Brennan L, Peng GM, Srinivasan N, Fox K R and Brown T, Nucleosides Nucleotides. Nucleic Acids, 2007, 26, 1283-1286.

41. Hong L, Miller P S and Seidman M M, Org Biomol Chem., 2008, 6(22), 4212-4217.

42. Chaudhuri N C and Kool E T, J Am Chem Soc., 1995, 117, 10434-10442.

43. Kumar A, The IUP J Chem., 2009, II(4), 47-54.

44. Glick G D, Osborne S E, Knitt D S and Marino Jr J P, J Am Chem Soc., 1992,114 , 5447-5448.

45. Glick G D, J Org Chem., 1991, 56, 6746-6747. 


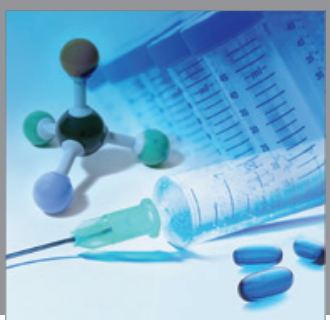

International Journal of

Medicinal Chemistry

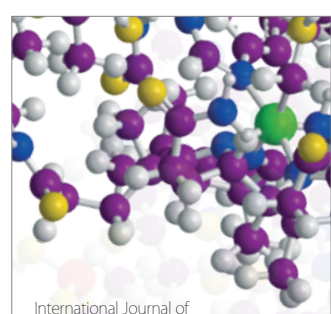

Carbohydrate Chemistry

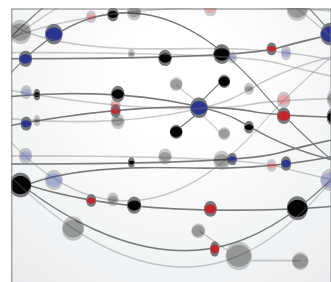

The Scientific World Journal
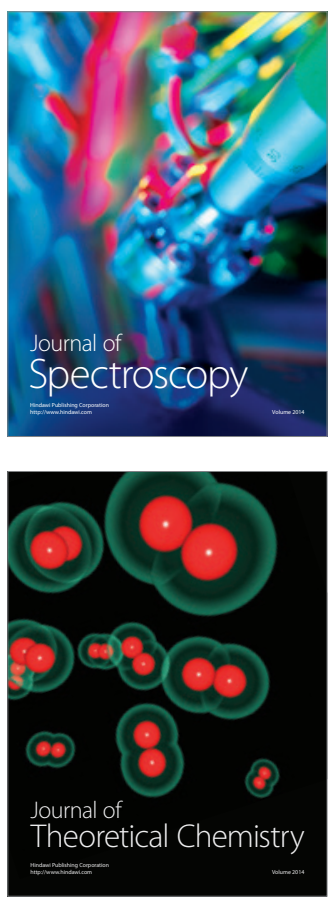
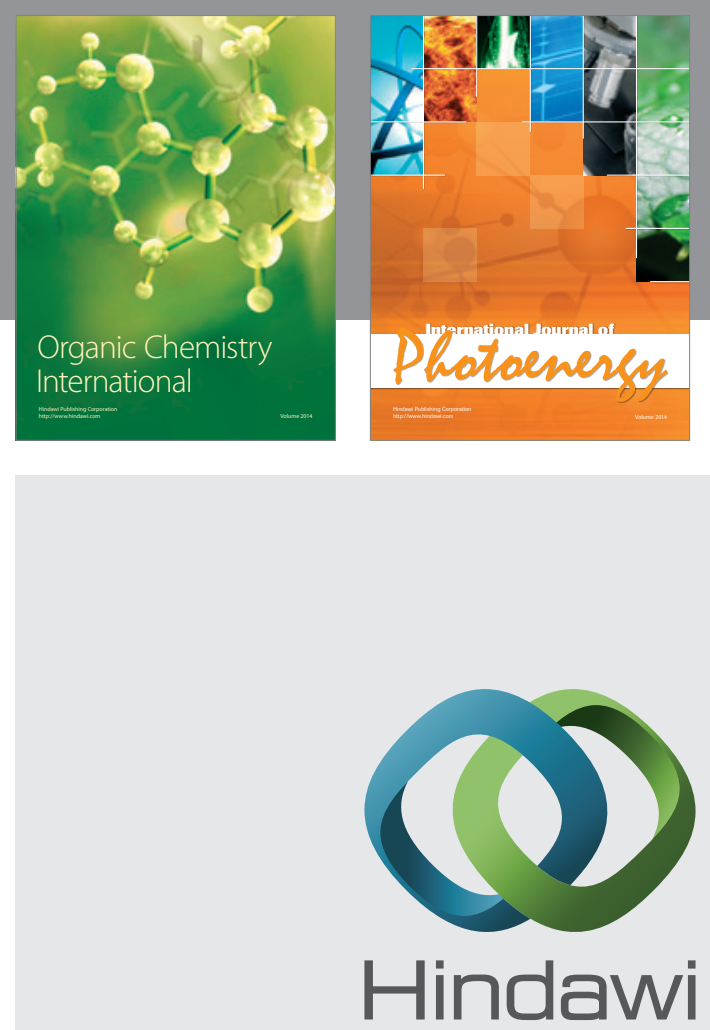

Submit your manuscripts at

http://www.hindawi.com
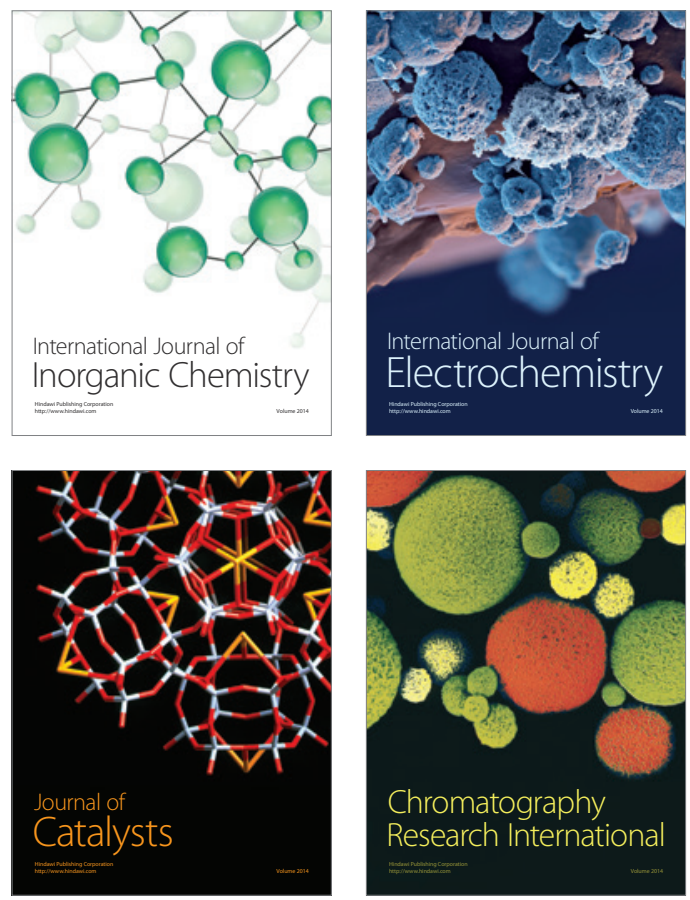
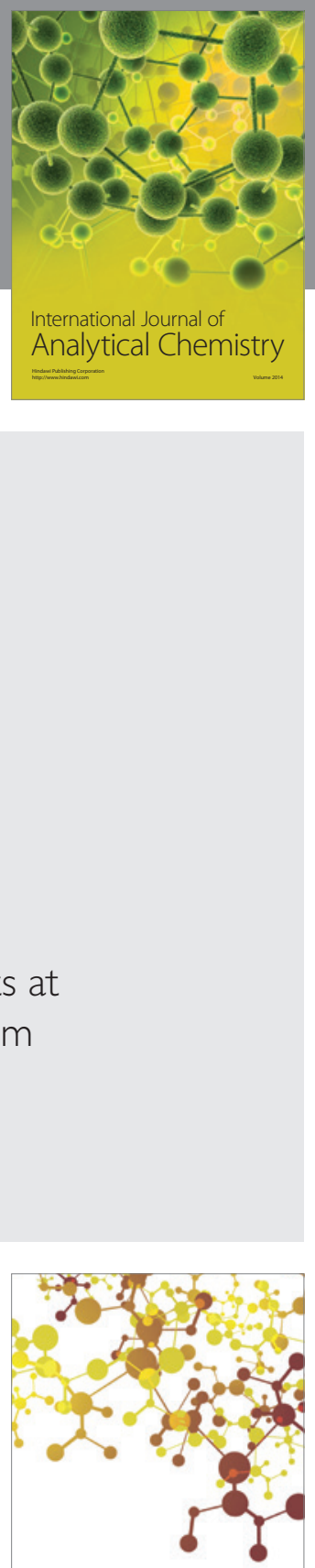

Journal of

Applied Chemistry
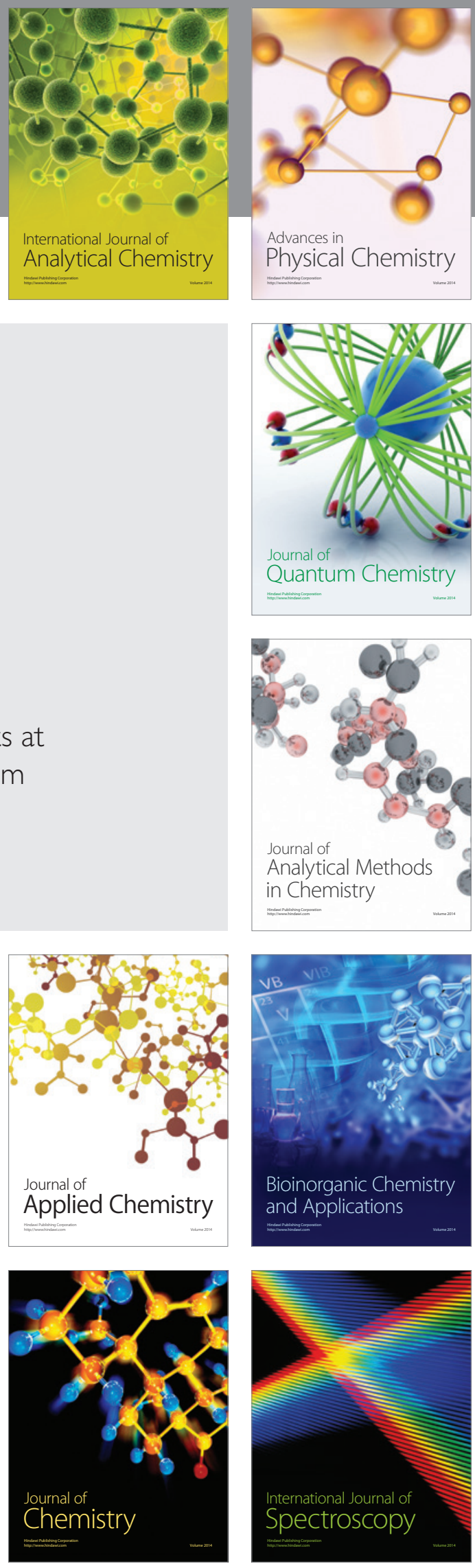